\title{
SYMBOLA, BASE DE DATOS DE DIVISAS O EMPRESAS HISTÓRICAS. UN RECURSO SOBRE CULTURA VISUAL, LITERATURA E HISTORIA EN INTERNET ${ }^{1}$
}

\author{
SAGRARIO LÓPEZ POZA \\ Universidade da Coruña \\ NIEVES PENA SUEIRO \\ Universidade da Coruña
}

\section{RESUMEN}

Symbola es una base de datos y biblioteca digital destinada a recopilar el mayor número posible de divisas o empresas históricas que usaron reyes, caballeros, damas, eclesiásticos, académicos, impresores, etc. entre los siglos XIV y XVII, tanto en el ámbito español como internacional. Se ofrece como una aplicación de acceso gratuito a través de Internet junto con otros recursos creados por el mismo grupo de investigación (SIELAE-Grupo Hispania, de la Universidade da Coruña -España-) con financiación del programa estatal I + D de España (proyectos BIDISO 5 y BIDISO 6). Este artículo expone la motivación del planteamiento del proyecto, objetivos, las especificaciones para el diseño conceptual de la base de datos y detalles sobre el desarrollo de la herramienta web de gestión y la interfaz web de consulta.

1 Este trabajo se ha realizado en el marco del proyecto Biblioteca Digital Siglo de Oro 6 (BIDISO 6), con referencia: PID2019-105673GB-I00, financiado por el Ministerio de Ciencia e Innovación de España por el programa estatal de Generación del Conocimiento (2020-2022), y se integra en el Grupo de Investigación Hispania (G000208) de la Universidade da Coruña. 
Palabras clave: Emblemática, divisas, empresas, cultura visual, base de datos, Edad Media, Renacimiento.

\section{ABSTRACT}

Symbola is a database and a digital library designed to collect the largest possible number of historical devices or imprese used by kings, knights, ladies, ecclesiastics, academics, printers, etc. between the fourteenth and seventeenth centuries, both in Spain and Internationally. Symbola is offered as a free access application through the Internet together with other resources created by the same research group (SIELAE-Grupo Hispania, de la Universidade da Coruña-Spain-) with funding from the Spanish state R\&D program (BIDISO 5 and BIDISO 6). This article presents the rationale for the project approach, objectives, the specifications for the conceptual design of the database and details on the development of the management web tool and the web query interface.

Keywords: Emblem Studies, Devices, Badges, Imprese, Visual Culture, Database, Middle Ages, Renaissance.

El impacto del desarrollo tecnológico, especialmente a partir de la creación y expansión de Internet, ha sido enorme en el progreso científico, y ha afectado también, de manera particular, al modo en que se conciben, planifican y se ejecutan los estudios humanísiticos y cómo se transfieren a la sociedad y se difunden sus resultados. Como señaló hace unos años E. Priani (2015) «las humanidades han entrado en un proceso de evolución para integrarse, de manera progresivamente más profunda, en la ecología de lo digital» ${ }^{2}$. Efectivamente, en la actualidad, gran parte de los procesos en los que interviene un humanista (consulta de fuentes primarias o secundarias, creación de contenidos - docentes, investigadores o divulgativos-, análisis de datos, edición de textos, difusión, etc.) utilizan herramientas, recursos o soportes digitales ${ }^{3}$, si bien puede percibirse todavía un remedo de las formas tradicionales impresas. Asistimos a un cambio de modelo de investigación que implica la modificación de metodologías, procesos hermenéuticos y epistemologías.

2 PRIANI SAISÓ, E., «El texto digital y la disyuntiva de las humanidades digitales», Palabra Clave, vol. 18, $\mathrm{n}^{\circ} 4,2015$, pp. 1215-1238.

3 Sin embargo, se percibe todavía un remedo de las formas tradicionales, especialmente en las ediciones académicas digitales, que no logran escapar del modelo del libro impreso como señalaba SPENCE, P., «Edición académica en la era digital: modelos, difusión y proceso de investigación», Anuario Lope de Vega 20, 2014, pp. 47-83. Sobre la imitación de modelos analógicos por parte de los medios digitales hay estudios muy interesantes; puede verse, por ejemplo, De la piedra al píxel. Reflexiones en torno a las edades del libro, editado por Marina Garone, Isabel Galina Russell y Laurette Godinas, México, UNAM, 2019. 
En los últimos años, un número creciente de grupos de investigación en disciplinas humanísticas han incorporado los métodos y herramientas digitales como medio de trabajo y modo de difusión de sus resultados. De esa imbricación entre humanidades y tecnología han ido surgiendo bases de datos y bibliotecas digitales que se han convertido en instrumentos de investigación fundamentales, pues permiten la consulta y utilización de un número ingente de datos, que, debidamente cruzados entre sí, dan lugar a resultados inimaginables hace solo unos años. Un ejemplo de estos nuevos recursos puede ser la base de datos de divisas históricas, Symbola, creada por el SIELAE (UDC), que pone al alcance del investigador las imágenes y datos de una gran cantidad de empresas o divisas utilizadas en la Edad Media y el Renacimiento europeo (la reproducción de la pictura, los datos de su mote, su significado, o la imagen y datos de sus propietarios).

\section{SEMBLANZA DEL EQUIPO}

El Seminario Interdisciplinar para Estudio de la Literatura Áurea Espanola $(\mathrm{SIELAE})^{4}$ de la Universidade da Coruña está formado por un equipo multidisciplinar con experiencia en la construcción de bibliotecas digitales sobre temas de la literatura y cultura del Siglo de Oro. Desde 1993 y hasta la fecha ha creado y mantiene las siguientes bibliotecas digitales: Biblioteca Digital de Literatura emblemática hispánica, Biblioteca Digital de Libros de emblemas traducidos al español, Catálogo y Biblioteca Digital de Relaciones de Sucesos, Biblioteca Digital Poliantea y, IBSO (Inventarios y bibliotecas del Siglo de Oro) y Symbola. Para facilitar la gestión de ese caudal de información y su consulta y uso desde un único punto de acceso, se creó el portal BIDISO $^{5}$ que agrupa las colecciones digitales; contiene bases de datos, ediciones digitalizadas (facsimilares y de textos transcritos) y bibliografía secundaria especializada que tiene que ver con: Emblemática, Relaciones de sucesos, Polianteas -enciclopedias, repertorios de lugares comunes, mitografías y fuentes de erudicióne inventarios de bibliotecas de la Edad Moderna. Recientemente el grupo puso

4 Fue creado por inciativa de Sagrario López Poza en 1996 como ente que agrupaba a investigadores de distintas áreas y universidades que trabajaban juntos en proyectos desde tres años antes. Puede consultarse más información acerca de sus líneas de investigación, miembros, proyectos o publicaciones en: <http: www.bidiso.es/Sielae>.

5 A partir del año 2013, todos los recursos producidos por el SIELAE se agruparon en el portal Biblioteca Digital Siglo de Oro (vid. Pena Sueiro 2017), integrado, a su vez, en la Red Aracne, que ofrece dieciséis recursos de investigación de diversos proyectos y grupos, con un metabuscador común. La red emplea el protocolo OAI-PMH y somos agregadores (data provider) de Hispana y Europeana, principales repositorios de recursos digitales de España y Europa respectivamente (para más información, vid. Alvite Diez y Pena Sueiro, 2020). 
en línea la base de datos de divisas o empresas históricas Symbola, cuyas caracterísiticas se detallan a continuación.

\section{PLANTEAMIENTOS DE SYMBOLA}

Symbola. Divisas o empresas históricas es un proyecto cuyos trabajos se iniciaron en noviembre de 2016, cimentados en un largo proceso de estudio sobre la emblemática llevado a cabo desde 1993 por miembros del grupo de investigación SIELAE. La presentación de la aplicación web (base de datos, interfaces de consulta y de administración, etc.) se efectuó en el III Congreso de la asociación Humanidades Digitales Hispánicas que tuvo lugar en Málaga en octubre de 2017. El presente artículo pretende exponer el proceso de elaboración de esta aplicación en los once meses indicados y las mejoras incorporadas tras las pruebas de la base de datos.

\section{El objeto de estudio: las divisas o empresas históricas}

Nuestro objeto de estudio son las divisas o empresas históricas ${ }^{6}$, que es una de las modalidades de la emblemática más interesantes, pero que ha sido insuficientemente estudiada hasta el momento. La nomenclatura ha provocado problemas para identificar el género y sus modalidades, ya que a lo largo del tiempo o según la especialidad de quien acometía su estudio, el concepto ha recibido diversos nombres: divisa, empresa ${ }^{7}$, invención ${ }^{8}$, letras de justadores, motes, etc.

6 Es decir, que nos consta que fueron usadas por personas que existieron en realidad, a diferencia de las divisas literarias, muy frecuentes, por ejemplo, en las novelas de caballerías o creaciones panegíricas para personas importantes, cuyo fin distaba mucho del uso que se daba a las divisas históricas.

7 En España, «divisa» o «empresa» se usaron como sinónimos, equivalentes a devise (en francés), device (en inglés) impresa e inventione (en italiano) o wahlspruch (en alemán). Para más detalles sobre etimología y nomenclatura, ver ROLET, A. «Aux sources de l'emblème: blasons et devises», Littérature, 145 2007/1, pp. 53-78 (p. 54). Entre los preceptistas del género, existe también diversidad terminológica: Paolo GIOVIO emplea indistintamente los términos «invenciones» $\mathrm{y}$ «empresas», aunque se decanta con frecuencia hacia este último en su Dialogo de las empresas militares y amorosas... con un razonamiento a esse proposito del magnifico Señor Ludovico Domeniqui [sic]... traduzido en romance castellano por Alonso de Ulloa. Añadimos a esto las empresas heroicas y morales del Señor Gabriel Symeón, en León de Francia, en casa de Guglielmo Roville, 1561. Los editores o comentaristas de Giovio: Domenichi, Ruscelli y Ammirato, privilegian el término impresa (empresa). Mucho tiempo después (1654), Emanuele TESAURO expone en Il cannocchiale aristotelico o sia idea delle argutezze heroiche vulgarmente chiamate imprese et di tutta l'arte simbolica et lapidaria..., Torino, Gio. Sinibaldo, 1654, todos los nombres que estas agudezas heroicas (argutezze heroiche), recibieron incluso desde tiempos antiguos, antes de que se convirtieran en un género: (glypta, specimen, argumentum, impresa y devise), pero él se centra en los términos impresa y devise.

8 Algunas creaciones realizadas ad hoc para ostentar en un torneo, justa o cualquier acto festivo, solían denominarse «invenciones», una modalidad de divisa de carácter más efímero, más vinculada a 
Estas creaciones ingeniosas de carácter simbólico, compuestas por lo general de la hibridación de imagen y palabra, adquirieron carácter lo bastante firme como para considerarse un género (con rasgos de forma y contenido bien identificables) en la cultura cortesana bajomedieval y renacentista. Se diferencian del sistema de representación de la Heráldica (los blasones simbolizan a la vez al sujeto y a su estirpe, y en su diseño poco puede intervenir el propietario). También se distinguen de los emblemas en cuanto a sus destinatarios, al tipo de mensaje que transmiten y el canal o soporte mediante el que lo expresan ${ }^{9}$. Las divisas representaban a su dueño, y se ostentaban como marca de identidad en diversos soportes y ocasiones.

Desde la segunda mitad del siglo XIV y hasta finales del siglo XVII ${ }^{10}$, los miembros de las familias reales, la nobleza, cortesanos (incluidas las damas), así como más tarde destacados hombres de negocios de la burguesía, se esforzaron en idear (solos o con ayuda de un poeta o un entendido en letras) una composición que, mediante una sentencia breve y a menudo en latín (mote -alma-) y una imagen (pictura-cuerpo-), representara sus aspiraciones heroicas más nobles, cierto rasgo de su carácter, o algún mensaje de enamorado ${ }^{11}$.

Estas creaciones constituían un sistema de comunicación entre las élites de los siglos XIV-XVII, en el cual un emisor (el propietario de la divisa) emitía un mensaje mediante un código simbólico en que intervienen imagen y palabras y que un eventual receptor, competente para descifrar ese código, había de interpretar correctamente. Dependiendo del emisor, el receptor al que se envía el mensaje, el canal o el soporte por el que lo hace y el contexto y situación, se produce una modalidad u otra del género. Esta función comunicativa, así como

mensajes pertinentes en un entorno determinado. Depende más del contexto y situación en que se exhibió el mensaje para comprender bien su significado, que pudo ser fácilmente interpretado en su momento y por unos receptores conocedores de las circunstancias, pero que, pasados los siglos, puede resultar difícil de interpretar.

9 Los emblemas se dirigen a un público general, mientras que las divisas envían un mensaje del propietario a unos pocos que sean capaces de comprenderlo (los cortesanos), que a menudo saben bastantes cosas de su vida y sus circunstancias, y gracias a ello cobra muchas veces sentido lo que comunica. El emisor del mensaje apela a la capacidad de descifrar agudezas de los espectadores, a quienes pone a prueba, esperando dejarles suspendidos y asombrados. Los emblemas, en cambio, pretenden ser entendidos sin muchas dificultades, y prueba de ello es que añaden un epigrama para aclarar la relación entre mote y pictura. Por lo general, el tipo de mensaje de un emblema es de carácter moral o didáctico, mientras que el de una empresa o divisa suele ser heroico, amoroso, etc. El canal y soporte mediante el que se expresan ambas modalidades emblemáticas es también distinto. Los emblemas se difunden sobre todo en libros, mientras que las divisas o empresas se ostentaban en una gran variedad de soportes.

10 Hay divisas anteriores y posteriores a esas fechas, pero es el rango más frecuente de tiempo de su uso.

11 Los conceptos más frecuentes expresados en las divisas o empresas solían ser ideales heroicos y amorosos, pero también pueden dar cuenta de contenidos de otra índole. 
su naturaleza simbólica y el carácter individual y personal de cada una de estas composiciones son rasgos que distinguen las divisas de otras modalidades emblemáticas (como los emblemas o los jeroglíficos).

A modo de ejemplo, veamos una divisa (Fig. 1), que según el humanista flamenco Jacob Typotius (inspirándose en unos diseños de Octavius de Strada) ${ }^{12}$, perteneció al rey Juan II de Aragón (1398-1479). Se nos muestra una imagen de una salamandra sobre el fuego, con el mote en latín DURABO («Perduraré»). La salamandra (o salamanquesa, como indica Covarrubias en su $\mathrm{Te}$ soro de la lengua-1611-), legendariamente se creía resistente al fuego. Esta afirmación fue sostenida por autores como Aristóteles, Plinio o San Isidoro de Sevilla a lo largo de siglos, así como en los bestiarios medievales ${ }^{13}$. Por ese motivo, se convirtió en símbolo de los constantes, firmes e inquebrantables. Así lo recoge Pierio Valeriano en sus Hieroglyphica (libro XVI, cap. XX) ${ }^{14}$. Ese es el concepto que el rey Juan II pretende que se asocie a su persona mediante la imagen elegida para su divisa, reforzando el mensaje con el mote, que manifiesta su determinación de perdurar pese a cualquier adversidad.

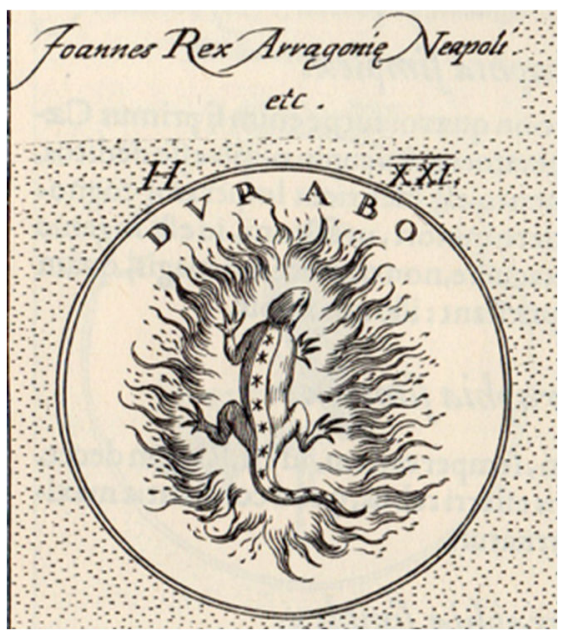

Fig. 1. Divisa del rey Juan II de Aragón. Jacob Typotius, Symbola Divina \& Humana, 1603, I, lám. 30, 3.

12 Los diseños manuscritos de Strada sirvieron de base a los catálogos impresos publicados por el humanista, político y jurisconsulto flamenco Jacob TYPOT (latinizado TYPOTIUS) que acabó como historiador en la corte del emperador Rodolfo II en Praga. Su colección de «Symbola» se publicó en tres volúmenes en Praga entre 1601 y 1603, con breves comentarios en latín sobre cada empresa y grabados de Aegidius Sadeler: TYPOTIUS, Jacobus, Symbola dinina \& humana pontificum imperatorum regum..., Praga, [s.i.], 1601-1603.

13 GARCÍA ARRANZ, J. J., «La salamandra: distintas interpretaciones gráficas de un mito literario tradicional», Norba-Arte, X (1990), pp. 53-68.

14 VALERIANO, P., Hieroglyphica sive de sacris Aegyptiorum literis commentarii, Basileae, [Michael Isengrin], 1556. 


\section{Algunas causas de la escasez de estudios sobre las divisas históricas}

Son varias las dificultades que han obstaculizado hasta ahora el estudio de las divisas o empresas, así como la variedad de realizaciones prácticas, la producción y evolución en el tiempo y otros datos que son fundamentales para poder trazar una teoría del género. Esta ha de estar basada en datos fehacientes que emanen del análisis de un gran número de divisas históricas y no, como se ha venido haciendo hasta ahora, en los preceptos indicados por tratadistas tardíos (de los siglos XVI y XVII), que la mayor parte de las veces ofrecen especulación desiderativa más que realidades objetivas. Una de las dificultades aludidas radica en que el género no encaja a la perfección en ninguna de las difusas fronteras disciplinares de los estudios divididos por áreas en el mundo académico, que han producido titubeos sobre a quiénes compete su estudio -especialistas en Literatura, en Arte, en Historia, en Lenguas Clásicas, en Heráldica-. La integración cada vez más frecuente de perfiles transversales en los equipos de investigación y la tecnología digital desarrollada en los últimos decenios ha venido a solucionar una parte de los obstáculos que impedían un acercamiento adecuado al estudio de las divisas o empresas históricas, que forzosamente ha de ser interdisciplinario.

Otras limitaciones han sido:

- La naturaleza efímera de muchas de estas composiciones, creadas a veces para un acontecimiento festivo, pasado el cual solo sabemos de ellas a través de un poeta que fue testigo y anotó el mote y, en ocasiones, describió con palabras la imagen.

- La gran variedad y dispersión de las fuentes (crónicas históricas, cancioneros, relaciones de sucesos manuscritas o impresas, etc.).

- La gran variedad y dispersión de los soportes en que se exhibieron (labradas en piedra, pintadas al fresco en paredes, azulejos, miniaturas en códices, mayólica, retratos, medallas, joyas, tapices, y un largo etcétera).

- La escasez de catálogos modernos.

No hay ningún catálogo que podamos llamar general sobre divisas o empresas históricas. Los primeros libros que reunieron diferentes empresas surgieron a mediados del siglo XVI en Francia e Italia. En 1551, el historiador y genealogista francés Claude Paradin publicó una colección de 118 Devises 
Heroïques (un grabado de la imagen ${ }^{15} \mathrm{y}$ el mote) cuyo objetivo era ayudar a creadores de divisas que precisaran de inspiración o modelos. La obra se reeditó con frecuencia a partir de entonces en varias formas y diferentes idiomas, y ejerció en Europa gran influencia. La segunda edición, de 1557, aporta un breve comentario en francés bajo la pictura y el mote, así como el nombre de la persona que usó la divisa ${ }^{16}$; además, el número de divisas aumenta a 182. En 1555 (tres años después de la muerte de su autor) se publicó una colección de empresas comentadas en forma de diálogo por Paolo Giovio, escrito en 1551: Dialogo dell'imprese militari et amorose. Esta editio princeps carecía de ilustraciones, que no se incorporaron hasta la edición de Ludovico Domenichi, impresa en Lyon por Guillaume Rouillé, en 1559. En los años siguientes aparecieron más ediciones en italiano y traducciones en otros idiomas. También en Lyon, en 1559, el polígrafo florentino Gabriele Simeoni, publicó una colección propia de divisas heroicas y morales ${ }^{17}$. Dos años después, en algunas ediciones de traducciones del diálogo de Giovio, en la empresa editorial de Rouillé (con la que colaboró Simeoni) se incluyó su colección de empresas a continuación de la de Giovio, en un solo volumen.

Con estas colecciones de divisas o empresas se puso de manifiesto que lo que había sido hasta entonces materia para discusión oral, reservada a cenáculos cortesanos y conversaciones de humanistas (no adecuada para tratados impresos) se había convertido en un producto editorial de éxito, que podía aportar pingües beneficios. Estos libros no solo interesaron a la nobleza y alta burguesía, ávida de conocer las agudezas empleadas por sus semejantes para estas creaciones, sino también a un gran número de artesanos diversos que se inspiraban en los diseños para sus trabajos. Así se advierte en varios testimonios. Por ejemplo, Pietro Bembo, en la posdata de una carta escrita en 1510 al Cardenal Ippolito d'Este, dice:

15 A partir de este momento denominaremos a la imagen pictura, término convencionalmente empleado en los estudios de emblemática.

16 PARADIN, C., Devises herö̈ques, Lyons, Jean de Tournes y Guillaume Gazeau, 1557.

17 SIMEONI, G., Le imprese heroiche et morali retrovate da M. Gabriello Symeoni Fiorentino, in Lyone, apresso Guglielmo Roviglio, 1559. Estudios recientes de Barsi y de Parnotte aportan nuevo conocimiento sobre el proceso de creación e impresión, basándose en el manuscrito de la Biblioteca Medicea Laurenziana de Florencia (ms. Ashburnham 1376) fechado en 1556: BARSI, M., «Les 'devises' illustrées de Gabriele Simeoni. Du manuscrit Ashburnham 1376 aux éditions publiées par Guillaume Rouillé», en Le savoir italien sous les presses lyonnaises à la Renaissance. Études réunies par Silvia D'AMICO et Susana GAMBINO LONGO, Genève, Droz, 2017, pp. 235-252 y Alexandre PARNOTTE, «Genèse et aventure éditoriale du 'Dialogo delle imprese militari et amorose' de Giovio et de 'Le imprese heroiche et morali' de Symeony chez Roville, 1555-1559, à la lumière du ms. Ashburnham 1376», en Le savoir italien sous les presses lyonnaises à la Renaissance. Études réunies par Silvia D'AMICO et Susana GAMBINO LONGO, Genève, Droz, 2017, pp. 489-559. 
«He pensado algo en torno a vuestra Empresa; pero este es un asunto más para la discusión que para escribir sobre él» ${ }^{18}$.

Y podemos comprobar en Il Cortegiano, de Baltasar de Castiglione, publicado en abril de 1528 en Venecia, que, al describirnos las actividades que se desarrollan en la corte ducal de Mantua, señala que, después de la cena, «si faceano imprese, come oggidi chiamiamo: dove di tali ragionamenti maraviglioso piacere si pigliava per esser, como ho detto, piena la casa di nobilissimi ingegni> ${ }^{19}$.

Especialistas en distintas materias imitaron a los primeros recopiladores de empresas y publicaron sus colecciones en la segunda mitad del siglo XVI y el primer cuarto del XVII en Francia e Italia. Desde entonces, y hasta los catálogos más modernos, ha habido disparidad de criterios sobre el campo por el cual han de organizarse las divisas o empresas:

- $\quad$ por el nombre del propietario ${ }^{20}$,

- $\quad$ por los corpora o motivos representados en las picturae ${ }^{21}$,

- $\quad$ por el mote,

- $\quad$ por el concepto 22

18 BEMBO, P., Lettere, edición crítica de Ernesto Travi, Bologna, Commissione per i Testi di Lingua, 1990-1993 (4 vols), vol. I, p. 38: «Io avea pure pensato non so che sopra le imprese di V. Rma. S. Ma sono cose più tosto da ragionare che da scrivere». (Apud CALDWELL, D., The Sixteenth-Century Italian Impresa in Theory and Practice, Brooklym, New York, AMS Press, 2004, p. 7, n. 18 -traducción nuestra-).

19 Il cortegiano del conte Baldesar Castiglione, anotado e ilustrado por Vittorio CIAN, Firenze, G. C. Sansoni, 1894, lib. I, p. 19. El traductor al español del libro de Castiglione, Juan Boscán, no parece estar familiarizado con la práctica que describe Castiglione, y alude a otra diferente, que era la costumbre de motejar, entretenimiento chistoso diferente del ejercicio bastante más elevado de tratar sobre empresas.

20 Claude PARADIN, Gabriel SIMEONI, Battista Pittoni \& Lodovico DOLCE, Girolamo RUSCELLI y Camillo CAMILLI clasificaron sus colecciones por individuos propietarios de las divisas. Igualmente, Octavius de Strada realizó sus dibujos de empresas y las agrupó por propietarios según categorías (emperadores, reyes de diversos países, príncipes, duques, papas, etc.).

21 Por ejemplo, Giovanni FERRO, a quien imitó Filippo PICINELLI con el repertorio de empresas que tuvo mayor difusión en la segunda mitad del siglo XVII y en el XVIII: Mondo simbolico... (1653), que alcanzó más de treinta ediciones ampliado y traducido del italiano original al latín por Augustin ERATH (Hieroglyphica). Puede decirse que, gracias a los ricos índices en varias lenguas y a la hábil taxonomía por corpora, es lo más parecido a una base de datos avant la lettre.

22 En menor medida se ocupan algunos autores de las empresas tomando el concepto como base de la organización del repertorio, y generalmente no tratan de divisas históricas, sino más bien de creaciones literarias, como Giulio Cesare CAPACCIO (Delle imprese, 1592) y Scipione BARGAGLI (que en 1578 publicó en Siena La prima parte dell'Imprese, con una segunda edición en 1589, y la veneciana de 1594, que reúne las tres partes de la obra: Dell'imprese). 
Entre los más modernos, parece que la organización por el mote se ha ido imponiendo, posiblemente porque son más las divisas que carecían de pictura que las que no tenían mote. Así, por ejemplo, salvo Fanny Bury Palliser (Historic Devices, Badges and War-Cries, 1870) que organizó su contenido por el nombre de propietarios de las divisas, los que siguen hicieron prevalecer en sus taxonomías el mote como elemento sustancial en torno al que se organiza el resto de la información: Alan R. Young publicó en 1988 The English Tournament Imprese (New York, AMS) que registra 521 divisas históricas empleadas en torneos en la Inglaterra de los Tudor; Mason Tung, en 2006, publicó Impresa Index, obra en que indexa 1.866 motes de empresas procedentes de diez colecciones publicadas en los libros principales del género (2.559 empresas); Philippe Palasi, en 2016: Mots, cris et devises emblématiques dans l'Europe occidentale médiévale et moderne, indexa 32.524 motes y Andrea Maceiras, en 2017: Empresas o divisas históricas: un catálogo basado en fuentes de 1511 a 1629, registra 675 divisas, organizadas por motes, con análisis de varios campos. Siendo algo tan importante, son escasísimos los catálogos que incluyen imágenes. El de Palliser ofrece dibujos de las divisas (pero son recreaciones, no reproducciones originales). De los mencionados, solo el de Maceiras aporta reproducciones originales de época (cuando existen y pueden reproducirse) o de un tiempo razonablemente posterior a la creación de las piezas.

\section{¿Por qué consideramos necesaria la creación de una aplicación web sobre divisas o empresas históricas?}

Los libros impresos mencionados son útiles y necesarios, pero limitados para realizar búsquedas. Dependemos de los índices, y a veces no son todo lo completos que nos gustaría. Como se ha dicho, unos organizan el contenido por nombres de los que en su día ostentaron las divisas; otros, por motes, y algunos catálogos antiguos se organizan por motivos pictóricos. Otro inconveniente es que suelen ser libros caros, de tiradas limitadas y a veces difíciles de conseguir. El que no incluyan ilustraciones es otra dificultad añadida. Y, en todo caso, no podemos cruzar datos.

Todos esos inconvenientes se resuelven con una base de datos online de acceso abierto, que permita registrar todos los datos pertinentes y acceder a ellos por medio de relaciones previamente establecidas como fruto de la experiencia del análisis. Y con una ventaja añadida: una base de datos siempre permite ampliar el contenido a medida que vamos sabiendo más sobre los propietarios o cualquiera de los campos de estudio. Si se descubre una nueva imagen, un nuevo dato, se pueden añadir. 
El único recurso electrónico previo al que queríamos crear era la base de datos Devise. Emblématique et héraldique à la fin du Moyen Age fundada por Laurent Hablot, basada en su tesis doctoral, dirigida por Michel Pastoureau y Martin Aurell, sobre divisas de príncipes europeos del final de la Edad Media y principios del Renacimiento (1350-1550), y defendida en 2001. La base de datos se presenta como un trabajo colaborativo entre una red de investigadores internacionales, y su núcleo lo constituyen las divisas francesas, con muy escasa presencia de las españolas o italianas, de las cuales hay muchísimo material pendiente de estudio. Su enfoque está más vinculado con la Heráldica que con la Emblemática (cuyos estudios tanto han evolucionado a lo largo del siglo XX). Desde la primavera de 2014 a 2019 el recurso estuvo disponible en Internet a través del Centre d'Etudes Supérieures de Civilisation Médiévale y los Services informatiques de l'Université de Poitiers, pero desde 2019 desapareció de la web durante más de un año, hasta que en otoño de 2020 resurgió en la plataforma SAPRAT (Savoirs et practiques du Moyen Âge au XIXe siècle), de la École Pratique des Hautes Etudes (Francia) ${ }^{23}$.

Los miembros del Seminario interdisciplinar para el estudio de la Literatura áurea española (SIELAE) consideramos que era necesario crear un Sistema de Información en web gratuito, compuesto por una base de datos sobre divisas o empresas históricas, y un software diseñado y construido en capas, con una parte pública de consulta y una parte privada (restringida por usuario y contraseña) para gestión. Sería de gran utilidad para el estudio de las divisas históricas, para poder realizar un análisis basado en datos fehacientes sobre la práctica real del uso de esta modalidad de la emblemática, que permitiría aportar nuevos planteamientos sobre su evolución y poder replantear la teoría del género. Por ello, se proyectó su creación como uno de los objetivos del proyecto Biblioteca Digital Siglo de Oro 5 (BIDISO 5), dirigido por Nieves Pena Sueiro, que consiguió subvención del Programa Nacional de I + D (Promoción General del Conocimiento), por el Ministerio de Economía y Competitividad y por el Fondo Europeo de Desarrollo Regional (FEDER) para trabajar entre los años 2016 y $2019^{24}$. En los años precedentes habían trabajado sobre divisas o empresas históricas dos miembros del SIELAE: Andrea Maceiras, con su tesis

$23<$ https://devise.saprat.fr $>$ [29/10/2020]

24 Referencia FFI2009-08113 (subprograma FILO). 
doctoral (defendida en 2016) ${ }^{25}$ y Sagrario López Poza, que la dirigió. En 2017 la tesis, se publicó como libro ${ }^{26}$.

El trabajo desarrollado había exigido una intensa reflexión teórica y metodológica. A ello se sumó haber podido constatar (del estudio de las casi setecientas divisas analizadas por Maceiras) que en la práctica hay notables diferencias con lo que expresaban como propio de la perfecta empresa los preceptistas tardíos. Habitualmente se ha considerado que las divisas transmiten altos ideales heroicos o amorosos, pero la observación de la praxis pone de manifiesto la existencia también de empresas cuyo contenido es religioso o incluso humorístico. En cuanto al mote, que en sus planteamientos ideales había de ser expresado en latín o lengua diferente de la del portador, se advirtió que los caballeros españoles emplearon principalmente el español, y que muchas veces, en lugar de una sentencia, se utilizaron versos para expresarlo. Asimismo, un número significativo de empresas entre las analizadas, presentan en sus picturae figuras humanas o miembros del cuerpo humano (algo censurado por Giovio). Aunque las divisas debían ser individuales (según preceptistas como Ruscelli), hay algunas familias que emplearon el mismo cuerpo o pictura o el mismo mote, con ligeras variaciones, en cuyo caso podría hablarse de divisas familiares. Esto son solo algunos ejemplos que nos ayudaron a tener en cuenta eventualidades que, de habernos fijado solo en lo que indicaban los tratadistas tardíos, habrían desfavorecido un diseño correcto de los datos de la aplicación que pretendíamos diseñar en el proyecto.

Nuestro objetivo era crear una base de datos capaz de acoger divisas históricas empleadas por reyes, caballeros, eclesiásticos, académicos, impresores, etc. desde los inicios del género, a finales de la Baja Edad Media, hasta sus manifestaciones en tiempos de plenitud (siglos XV-XVI) y su declive a finales del siglo XVII. No limitaríamos el ámbito geográfico (dando cabida a empresas españolas pero también de cualquier lugar de Europa o América), y nos basaríamos en una diversidad de fuentes, no solo las textuales.

25 Empresas o divisas (invenciones y letras) de reyes, caballeros y eclesiásticos españoles: un catálogo basado en fuentes de 1511 a 1629.

26 MACEIRAS, A., Empresas o divisas históricas: un catálogo basado en fuentes de 1511 a 1629, A Coruña, SIELAE \& Society for Emblem Studies, 2017. 


\section{DISEÑO E IMPLEMENTACIÓN DE LA BASE DE DATOS SYMBOLA}

La creación de una aplicación de este tipo exige un orden en el proceso:

- modelado de datos,

- diseño conceptual de la base de datos, las pruebas y correcciones precisas realizadas, las tecnologías de desarrollo (especialmente interoperabilidad, accesibilidad, etc.),

- diseño y desarrollo de la herramienta de gestión web de acceso restringido (administración),

- diseño de la interfaz de consulta,

- alimentación de BD para probar su funcionalidad, advertencia de errores y corrección, etc.,

- redacción de guía de uso y procedimiento para investigadores y gestores de la aplicación, supervisores y usuarios,

- alimentación de datos por investigadores del equipo, supervisión de cada ficha por la supervisora y publicación de las fichas.

\section{Especificaciones para el modelado y diseño conceptual de la base de datos}

Para el diseño conceptual de la base de datos Symbola partimos de la especificación de requisitos derivada de nuestro conocimiento experto previo, por las razones ya expuestas. Sagrario López Poza y Nieves Pena Sueiro (del equipo del proyecto BIDISO 5), con asesoramiento pertinente de los demás miembros del proyecto -José Julio García Arranz, Carlota Fernández Travieso, Cirilo García Román- trabajamos en colaboración con los ingenieros informáticos Ángeles Saavedra Places y Carlos Rodríguez Corral, miembros del Laboratorio de Bases de Datos de la Universidade da Coruña y con su empresa spin-off, Enxenio, especializada en realizar desarrollos informáticos innovadores a medida en Bibliotecas Digitales y sistemas de producción y distribución de contenidos digitales. Ellos también se ocuparon del desarrollo tecnológico. La empresa Cirugía Gráfica (Madrid) se ocupó del diseño gráfico de la interfaz de consulta.

La DIVISA es la entidad central que representa los elementos primarios catalogados en la base de datos (en adelante abreviamos como BD), y con la que se relacionan todas las demás entidades. Cada divisa pertenece a un PROPIETARIO y los focos principales de análisis son el MOTE, la PICTURA (cada uno lleva asociados aspectos particulares de análisis) y el SIGNIFICADO. De 
cada divisa que registramos y analizamos se ofrecen unos comentarios que pretenden integrar todo lo que conocemos sobre el propietario, la divisa y su significado (véase el diagrama de clases -Fig. 2-).

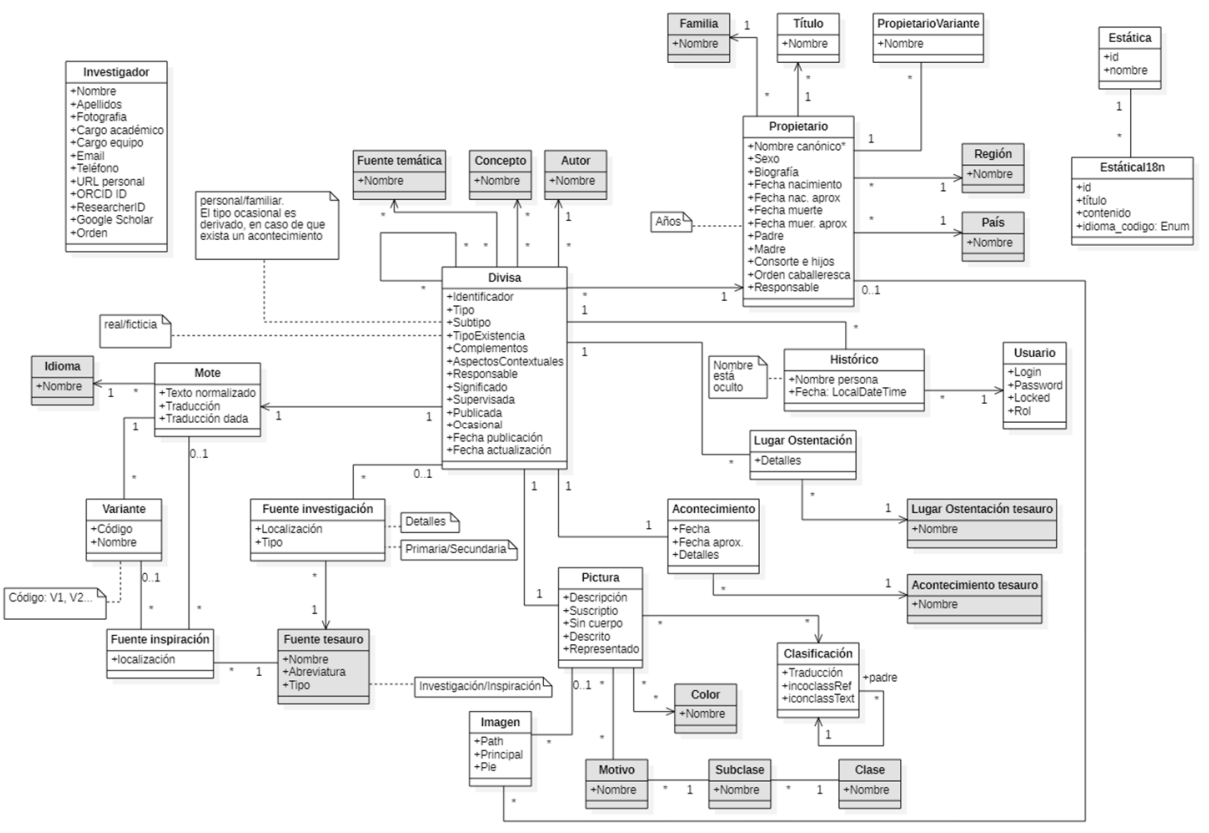

Figura 2: Diagrama de clases entidad-relación de Symbola.

Atributos de DIVISA son, además del identificador (campo autogenerado), el tipo (personal o familiar) ${ }^{27}$ y el subtipo (heroica, amorosa religiosa, marca de impresor, otras). Se añaden elementos que proceden del análisis, como conceptos, fuentes temáticas y autor. Por conceptos entendemos los términos abstractos que resumen valores morales, aspiraciones, etc. que el propietario de la divisa desea transmitir. Hemos elaborado un tesauro con los más frecuentes, para poder seleccionar y no tener que escribir cada vez. Si no encontramos allí el idóneo, se puede crear y queda incorporado al tesauro. El campo fuentes

27 Algunos de los considerados preceptistas del género indican la inconveniencia de que las divisas puedan ser heredadas por los descendientes. Así, RUSCELLI, lo expresa claramente: «Non debbono per alcun modo essere ereditarie, sì come sono l'Arme; né debbono usarsi da i figliuoli o da i nepoti, né da altri discendenti doppo la morte de' padri, degli auoli, ò de gli altri maggiori loro. Anzi né ancor uiuendo i padri si conuien che i figliuoli usino l'Imprese loro» (Discorso 189-190). Sin embargo, el estudio de Maceiras puso de manifiesto que hubo en España divisas familiares, lo que nos ha inducido a considerar señalar esa circunstancia cuando la conocemos. 
temáticas registra si la divisa está inspirada en temas muy conocidos de la $\mathrm{Bi}$ blia, la Mitología, etc. Asimismo, si se conoce el autor de la divisa (algo muy poco frecuente) podemos añadirlo en el campo autor. También se registran Aspectos contextuales, como los lugares de ostentación de la divisa si se saben (en la cimera, bordada en la gualdrapa del caballo, etc.) y el acontecimiento donde tenemos constancia de que se usó (y en su caso, fecha). Además, puede insertarse un comentario sobre estos y otros aspectos.

De la entidad MOTE se registran: texto normalizado, idioma, traducción actual, traducción original (si la tuviera), variantes y fuentes de inspiración.

La entidad PICTURA requirió de amplia reflexión para poder reflejar la variedad con que nos encontrábamos al analizar la praxis real de las divisas ya analizadas, pues se daban distintas circunstancias y todas ellas habían de registrarse. En algunas ocasiones la divisa carece de pictura porque fue concebida solo con mote; es decir, que la falta de cuerpo fue deliberada. Otras veces, no podemos hoy disponer de la imagen física, aunque originalmente la tuviera, algo que sabemos porque nos ha llegado una descripción de ella en las fuentes de que nos servimos. En estos casos, la carencia es accidental. Eso implica que los campos de análisis de la clase pictura pueden aplicarse no solo a imágenes físicas conservadas, sino también a las que no se conservan, pero de las que tenemos una descripción con palabras, algo muy frecuente cuando tomamos como fuente los cancioneros. En el diseño de la BD decidimos que pudieran seleccionarse tres posibilidades: «sin cuerpo» (reservada para cuando sabemos que la divisa solo tenía mote); «descrito» (cuando tenemos una descripción con palabras de lo que fue la pictura aunque no nos haya llegado testimonio físico alguno) y «representado» (para casos en que disponemos de una o más imágenes físicas como testimonio). En este último caso, podemos incorporar las representaciones figuradas en la $\mathrm{BD}$ en formato .jpg o .png, añadiendo un texto que indique la procedencia (pie de imagen). Si las imágenes son varias, se marcará cuál debe aparecer como primera en la interfaz de consulta, y sobre ella se realizará nuestra particular descripción, siendo lo más fiel posible a lo que aparece en la fuente textual de donde tomamos los datos.

Tanto para los casos en que dispongamos de «descripción» en la fuente de donde tomamos los datos o de «representación figurada» (es decir, una imagen) se registran los motivos que formaban parte de la pictura. En el diseño de la BD hemos implementado la opción de añadir una codificación Iconclass, el sistema de clasificación alfanumérico especializado en iconografía para aplicar a documentos visuales más usado por museos e historiadores del arte del mundo, con 28.000 términos ordenados jerárquicamente distribuidos en diez categorías 
principales. Permite recuperar motivos representados en las picturae y asociarlos semánticamente con otros similares. Iconclass está siendo traducida al español, y esperamos introducir los códigos más adelante. Mientras tanto, seguimos una taxonomía particular para los motivos pictóricos basada en un tesauro estructurado en jerarquías: 553 motivos agrupados en 51 subclases y en 10 clases, tipo de clasificación que permite recuperar las divisas por los motivos representados y a la vez hacer estudios cuantitativos sobre los diferentes tipos de motivos empleados en las mismas.

Suscriptio es un campo asociado a la entidad PICTURA reservado para los casos en que tenemos un testimonio textual (ya sea en la fuente primaria o en otra antigua) en que se describe la divisa; con frecuencia aclara el significado o la intención. A veces son palabras del propietario que indican cómo es su divisa y lo que significa; otras, son palabras de un cronista, testigo de vista o contemporáneo, por lo que su testimonio merece ser registrado por la importancia que tiene. Cuando sabemos que los colores son significativos, usamos el tesauro de colores ampliable para especificar los pertinentes a la pictura concreta ${ }^{28}$.

Significado es un campo donde el investigador expresa con pocas palabras, pero precisas, el sentido global del conjunto de la composición que consideramos una divisa.

La entidad PROPIETARIO reúne la información sobre la persona que ostentó la divisa según nuestras fuentes. Los atributos y clases que registran las propiedades de los propietarios son: nombre canónico del propietario, variantes del nombre, fechas (de nacimiento y muerte -con posibilidad de señalar si son aproximadas-), género, títulos, padre, madre, consorte(s) e hijos, biografía, familia, orden caballeresca, región y país. Además, podemos añadir imágenes asociadas a propietario (retratos, blasón, etc.) con el pie de imagen correspondiente.

FUENTES DE INVESTIGACIÓN es una entidad que acoge el tesauro de fuentes (y abreviaturas) de donde se toman los datos que tenemos sobre las divisas. Quien inserta los datos solo ha de seleccionar la abreviatura desde la aplicación de administración y detallar la localización precisa (capítulo, páginas, etc.). Eso garantiza que no haya errores al teclear el título de la fuente. Hay dos tipos de fuentes: «fuentes primarias» (los textos -manuscritos o impresosque mencionan las divisas, sus propietarios, los acontecimientos donde se

28 Respecto a la importancia de los colores y las explicaciones al respecto de Ruscelli, ver LÓPEZ POZA, S., «Emblemática aplicada y artificios de la cultura visual en los juegos caballerescos del Siglo de Oro», en J. M ${ }^{\text {a }}$. DÍEZ BORQUE (dir.), I. OSUNA y E. LLERGO (eds.), Cultura oral, visual y escrita en la España de los Siglos de Oro, Madrid, Visor, 2010, pp. 413-462 (en pp. 422-423). 
emplearon las divisas, etc...) y «fuentes secundarias» (estudios sobre el propietario, la divisa, el acontecimiento, etc.), que coadyuvan a una mejor comprensión y análisis de la divisa.

Podemos consignar también si advertimos que una divisa puede tener relación con otras, marcando alguna de estas opciones: «heredada de», «heredada por», «similar a», «inspirada en», «sirve de inspiración a», etc.

El responsable de redacción de cada ficha de una divisa y de cada ficha de un propietario registra su nombre, de modo que, tras pasar por el filtro del supervisor (investigador administrador que revisa y autoriza la publicación en Internet) se genera automáticamente una referencia bibliográfica que el autor o autores pueden incorporar a su producción científica (con ISSN 2531-3118).

\section{Aspectos técnicos}

El diseño conceptual de Symbola se ha documentado usando el modelo clases UML, con una notación más sucinta que la que usa el modelo EntidadRelación y, por lo tanto, más adecuada para describir una base de datos de esta complejidad (Fig. 2). Se ha implementado en PostGreSQL, un Sistema Gestor de Bases de Datos de uso libre. El diseño de datos se materializó en una base de datos con 39 tablas y un total de 160 atributos. Para una gestión más eficiente, las tablas se organizaron en tres esquemas: divisa, tesauro y común. El esquema divisa está formado por las 19 tablas que almacenan los datos relacionados con la catalogación y/o análisis de las empresas. El esquema tesauro cuenta con 16 tablas que corresponden con las clases marcadas en gris en el modelo de datos y las materializaciones de las relaciones muchos a muchos $\left(*_{-} *\right)$. En el esquema común se agrupan las tablas que dan soporte a funcionalidades e información que usan las herramientas de gestión y la web pública de consulta. Para almacenar y organizar las imágenes de las picturae y los propietarios, se preparó un sistema de archivos que enlaza con la base de datos a través del atributo Path de la tabla Imagen.

\section{Herramienta de gestión}

En la construcción de las aplicaciones de gestión y consulta (así como de la base de datos) hemos utilizado ${ }^{29}$ :

29 Sintetizamos lo ya expuesto por Sagrario LÓPEZ POZA y Ángeles SAAVEDRA PLACES, «Symbola: divisas históricas (emblemática personal) en la Europa medieval y moderna. Diseño e 
- para la programación, Java 2 Enterprise Edition (J2EE),

- en el lado servidor, hemos utilizado Spring Framework, en particular, las librerías Spring Security y Spring Boot, e Hibernate; y,

- en el lado cliente, AngularJS y, como complemento de este framework, los lenguajes HTML5, CSS3, JavaScript, JQuery y BootStrap.

La herramienta web de gestión permite el trabajo colaborativo para introducir la información almacenada en la base de datos y en el sistema de archivos multimedia. A través de la entidad USUARIOS (identificados con un login y clasificados por un rol, la herramienta distingue a usuarios «administradores» (con permisos de edición y publicación) de «investigadores» (que solo tienen acceso a sus propias fichas). Cualquier modificación realizada queda registrada en la entidad HISTÓRICO, asociada al login de quien lo realizó. Cada ficha permanece oculta a los usuarios de la interfaz pública mientras no es marcada como Publicada, lo cual solo puede hacer quien tiene rol de «administrador».

Los tesauros se van alimentando automáticamente a medida que en las divisas aparecen nuevos valores. Para la gestión de los tesauros se diseñaron unas interfaces de gestión de datos basadas en formularios que ofrecen un listado, en primer término, y que permiten acceder a todos los datos a partir de cada elemento de la lista; para la gestión de las tablas Motivo, Clase y Subclase (en las que se clasifican los motivos), se diseñó una gestión en línea, inspirada en una hoja de cálculo, que permite acceder en una única pantalla a todos los motivos para su organización y gestión.

\section{Interfaz de consulta}

La página principal de Symbola se presenta en dos lenguas, a elegir: español o inglés. Ofrece información sobre el proyecto y objetivos, proporciona enlaces a trabajos sobre el proceso de diseño e implementación y a unas indicaciones de uso de la base de datos. Permite acceder a los datos del equipo que se ocupa de su gestión y alimentación y da información de las condiciones de uso de la base de datos bajo la licencia «Creative commons Reconocimiento - NoComercial - SinObraDerivada (by-nc-nd)».

implementación de la base de datos y la interfaz de consulta», en N. RODRÍGUEZ-ORTEGA (coord.). «Humanidades digitales: sociedades, políticas, saberes II». Artnodes, n ${ }^{\circ}$ 23, 2019, pp. 49-61. $<$ http://dx.doi.org/10.7238/a.v0i23.3216>. 
Desde la página principal de la interfaz de consulta se puede acceder a todo el listado de propietarios, al de motes y al de motivos pictóricos de las divisas ya publicadas. Si se desea utilizar motores de búsqueda, hay dos posibilidades: una búsqueda simple y otra avanzada (Fig. 3), donde pueden seleccionarse campos que pueden ayudar mucho en la pesquisa y discriminación (de forma simple o combinada): por ejemplo, buscar por nombre del propietario, por tipo o subtipo de divisa, por motivos pictóricos, por mote, por idioma del mote, discriminar si deseamos resultados de divisas de hombres o mujeres, por familia, por concepto, por rangos de años, por países, por acontecimiento, si la divisa era ocasional (es decir, empleada solo para un festejo), etc. Por último, hemos añadido la posibilidad de recuperar las divisas según la fuente primaria que proporcionó los datos principales en que nos basamos.

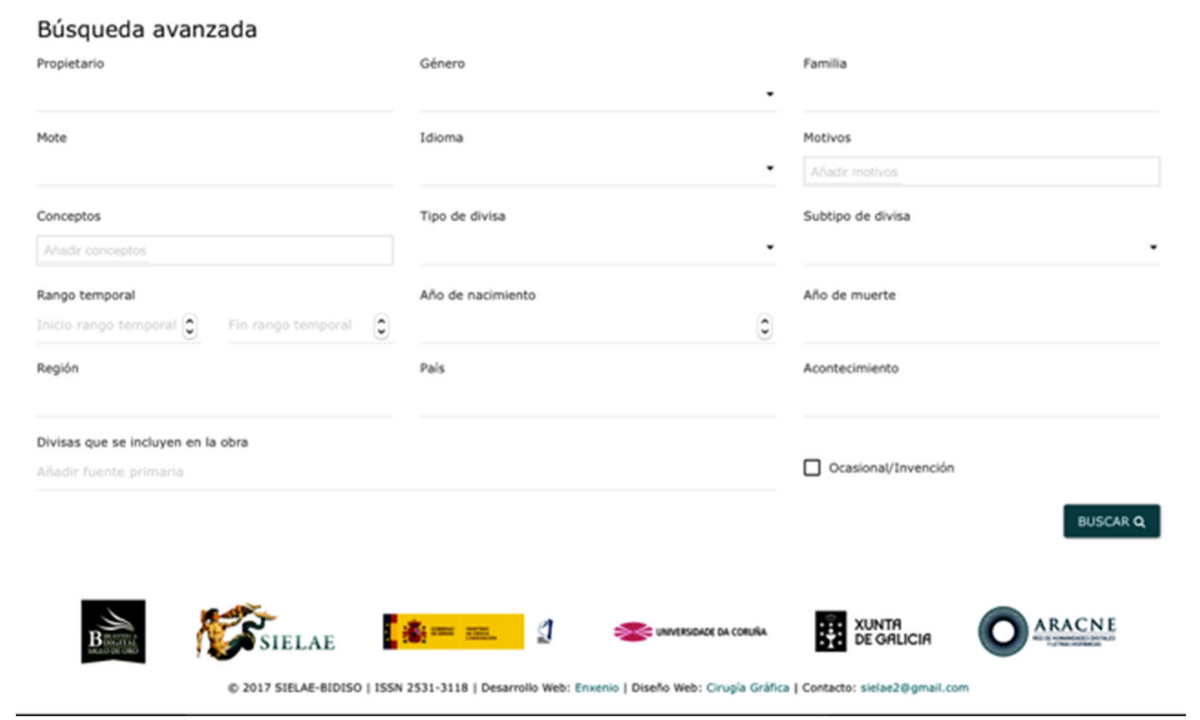

Fig. 3. Búsqueda avanzada en Symbola.

La ficha que arroja una consulta (Fig. 4) se presenta en forma de artículo, con tres secciones o columnas: a la izquierda, todo lo relativo al propietario, a la derecha, las ilustraciones de las divisas, si las hubiere, y en el centro, todo lo relativo al análisis de la divisa: el mote, su traducción (si es en otra lengua), el tipo y subtipo de divisa, los datos relativos a la pictura (si no tiene cuerpo, si lo tiene descrito, si disponemos de una representación figurada, la descripción del cuerpo, qué conceptos pretende transmitir -por ejemplo: prudencia, cautela, 
etc.-), el significado de la divisa y un comentario global. Aparecen las referencias bibliográficas (primarias y secundarias) y cómo debe citarse el artículo, del que aparecen como autores las personas que han intervenido en el estudio de la divisa, el registro de los datos y su supervisión. Los contenidos se ofrecen con licencia «Creative commons Reconocimiento - NoComercial - SinObraDerivada (by-nc-nd)».

El diseño de la interfaz de usuario es adaptativo (Responsive-Design) lo cual permite ajustarse a distintos tamaños de pantalla y resoluciones de los dispositivos móviles y ordenadores.

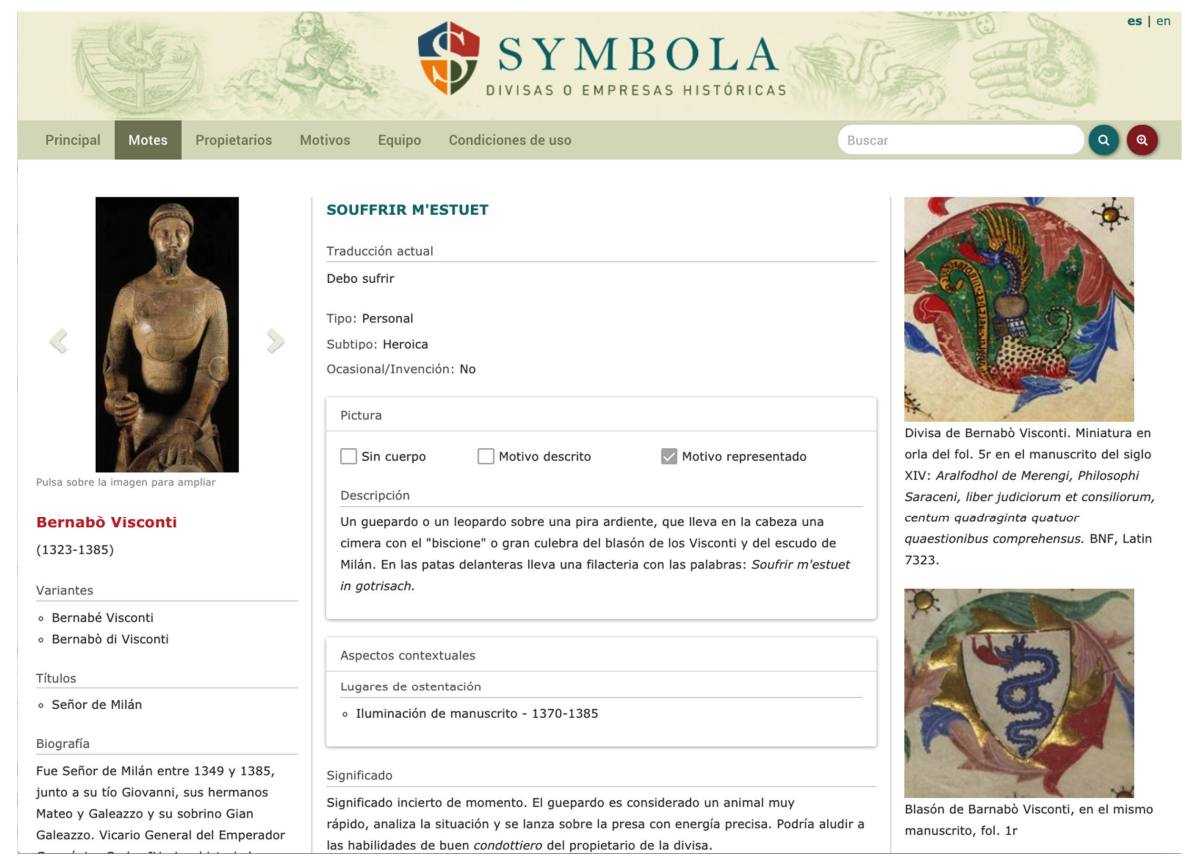

Fig. 4. Fragmento superior de un artículo ofrecido por la interfaz de consulta de Symbola.

\section{In itinere. Prospección de futuro}

Symbola está operativa para el público desde octubre de 2017, accesible en la dirección $<$ https://www.bidiso.es/Symbola $>$. El equipo que la gestiona y alimenta se ocupa no solo de las tareas de esta base de datos, sino de otras labores de los proyectos BIDISO (recientemente hemos conseguido financiación estatal para el proyecto BIDISO 6 (2020-2022). Esa circunstancia no permite 
avanzar tan rápidamente como querríamos en la alimentación de la base de datos. Las divisas analizadas son muchas más de las que se pueden procesar y publicar en tiempo breve, pues aspectos como el de aportar una síntesis de la biografía del propietario, buscar imágenes, etc. ocupan muchísimo tiempo, dado que algunos de esos individuos vivieron en los siglos XIV o XV y la información es escasa o difícil de conseguir. En este momento (octubre de 2020) tenemos registradas 397 divisas, (con su análisis y estudio), así como las biografías de 309 propietarios. Pendientes de publicación porque están en distintas fases de supervisión (y para completar con imágenes, etc.) tenemos 139. Están ya publicadas y en acceso libre 258 .

Una vez que se inserten las más de setecientas divisas ya analizadas, seguiremos incorporando registros de diversas fuentes (textuales y no textuales) que tenemos localizadas o en proceso de estudio. Uno de los miembros del equipo, Cirilo García Román, trabaja en la traducción del latín al español de las glosas de las divisas recopiladas por Salomon Neugebauer (Symbola Heroica1619-) importantes para un mejor conocimiento de las 202 divisas de los principales monarcas europeos y de su nobleza más selecta. Se irán incorporando a la base de datos en cuanto podamos (las divisas de monarcas españoles y franceses están listas para su introducción), así como otras colecciones menos conocidas.

\section{LOGROS DEL GRUPO}

Tras la presentación del prototipo de la nueva base de datos en el XI Congreso Internacional de la Society for Emblem Studies que tuvo lugar en Nancy en julio de 2017, en el mes de octubre, se realizó la presentación oficial de la base de datos Symbola (ya plenamente operativa y en línea) a la comunidad investigadora, en el III Congreso Internacional de la Sociedad de Humanidades digitales Hispánicas, celebrado en la Universidad de Málaga. En el mes de mayo de 2018, el grupo organizó en la biblioteca del convento de San Francisco de Santiago un seminario de investigación en el que participaron, además de miembros del equipo, investigadores invitados del CSIC, de la Universidad de Zaragoza o de la Universidad de Coímbra (Portugal), así como un nutrido número de asistentes. El seminario se completó con la exposición de libros de emblemas y obras afines conservados en la biblioteca del citado convento. Algunas de las ponencias del seminario se recogen en un monográfico de la revista Janus 8 (2018). 
Entre los días 17 y 18 de diciembre de 2019 secelebraron en la BNE las Jornadas Literatura Aurea y Humanidades Digitales, en las que el equipo presentó a la comunidad interesada los resultados de los 25 años de trabajo del grupo SIELAE. En la primera sesión, dedicada a los estudios sobre Literatura emblemática y sus modalidades, Sagrario López Poza, y Cirilo García Román trataron sobre dos libros de divisas; uno casi desconocido - un manuscrito francés con «invenciones» dibujadas en color $^{30}-\mathrm{y}$ el impreso de Salomon Neugebauer respectivamente; José Julio García Arranz realizó un estudio sobre las divisas de tema amoroso.

El grupo SIELAE ha conseguido en los tres últimos años revitalizar los estudios de una modalidad de la literatura emblemática que había quedado desatendida a pesar del interés que despertó durante siglos su uso como sistema de identificación personal y su práctica en los círculos humanistas. La base de datos Symbola ha venido a ocupar un papel relevante para los estudios de cultura visual y simbólica de la Baja Edad Media y la Edad Moderna, dando lugar a un buen número de presentaciones en congresos y publicaciones.

\section{IMPACTO}

Tras los esfuerzos de presentación y difusión de la base de datos de divisas históricas en congresos internacionales, que sin duda repercutieron en el uso y la notoriedad de Symbola, se vio la necesidad de instalar una aplicación que nos permitiese conocer el impacto generado en la sociedad. Para medir este impacto (número de visitas, número de consultas, tiempo de duración de estas, registros más buscados, ubicación de los usuarios, idioma utilizado, dispositivo y sistema empleado para la consulta, etc.) el equipo decidió utilizar los servicios que ofrece Google Analytics en su versión gratuita. Esta aplicación nos ha permitido saber, por ejemplo, que entre octubre de 2019 y octubre de 2020 visitaron la base de datos 3.469 usuarios visualizando 12.770 páginas web (Fig. 5), utilizando para ello tecnologías variadas (el sistema operativo Windows es el más usado). Las consultas se hicieron sobre todo desde España, pero también desde México, Italia, Francia o Estados Unidos.

Symbola es una base de datos creada por un equipo multidisciplinar, con software libre, que ofrece al interesado datos e imágenes, resultado del análisis experto sobre una modalidad emblemática, las divisas o empresas, de uso muy

30 LÓPEZ POZA, S., «Divisas ocasionales o invenciones españolas en un cancionero manuscrito del duque Charles III de Croÿ», en Hipogrifo, $\mathrm{n}^{\circ}$ 8.1, 2020, pp. 453-469, DOI: http://dx.doi.org/10. 13035/H.2020.08.01.31 
extendido en Europa en la baja Edad Media y la Edad Moderna, cuyo estudio resulta esencial para el conocimiento de la cultura simbólica y visual de la época.

La base de datos Symbola cumple los principios FAIR ${ }^{31}$ (Encontrable, Accesible, Interoperable y Reutilizable) y muestra, una vez más, que la tecnología puede ser una gran aliada para el avance en el conocimiento de los estudios humanísticos. Como otros recursos generados por el SIELAE, se ha incorporado a la red Aracne, lo que posibilita compartir los metadatos de los recursos digitales a través del protocolo OAI-PMH siguiendo las especificaciones del conjunto de metadatos ESEl. La Red Aracne ha desarrollado un metabuscador que permite realizar búsquedas de manera conjunta en todos los recursos y bibliotecas digitales integradas en la red, o seleccionar solo los que interesen.

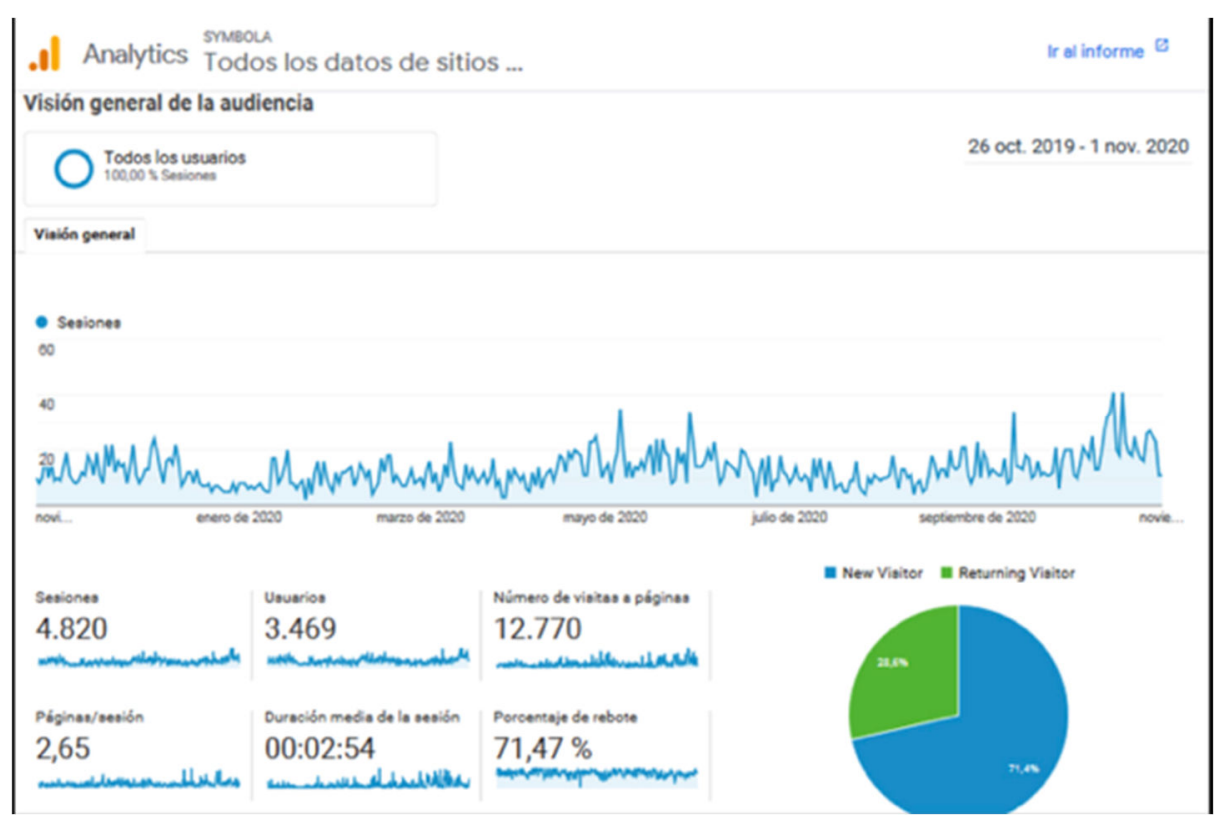

Fig. 5. Visión general de la audiencia de Symbola.

31 En marzo de 2016 se publicaron en la revista Nature Scientific Data «The FAIR Guiding Principles for scientific data management and stewardship», que enseguida fueron adoptados por la comunidad internacional como las características esenciales que debe tener todo recurso científico digital. Pueden consultarse en: https://www.nature.com/articles/sdata201618. 


\section{BIBLIOGRAFÍA}

ALVITE DÍEZ, M M L. y PENA SUEIRO, N., «Colecciones digitales patrimoniales especializadas. Estudio de la Red ARACNE», en TRAMULLAS SAZ, J., GARRIDO PICAZO, P., y MARCO CUENCA, G. (coords.), Actas del IV Congreso ISKO España-Portugal 2019, XIV Congreso ISKO España, Zaragoza, Sociedad Internacional para la Organización del Conocimiento (ISKO)-Capítulo Ibérico, 2020, pp. 185-195.

BARGAGLI, S., Dell'imprese, Venetia, appresso Francesco de Franceschi, 1594. BARSI, M., «Les 'devises' illustrées de Gabriele Simeoni. Du manuscrit Ashburnham 1376 aux éditions publiées par Guillaume Rouillé», en S. D'AMICO y S. GAMBINO LONGO (eds.), Le savoir italien sous les presses lyonnaises à la Renaissance, Genève, Droz, 2017, pp. 235-252

BEMBO, P., Lettere (edición crítica de E. TRAVI), Bologna, Commissione per i Testi di Lingua, 1990-1993 (4 vols.).

CALDWELL, D., The Sixteenth-Century Italian Impresa in Theory and Practice, New York, AMS Press, 2004.

CAMILLI, C., Imprese illustri di diversi, Venetia, Francesco Ziletti, 1586.

CAPACCIO, G. C., Delle imprese, Napoli, ex officina Horatij Saluiani, 1592.

DOLCE, L., Imprese nobili et ingenose di diversi prencipi et d'altri personaggi illustri nell'arme et nelle lettere, Venetia, presso Girolamo Porro, 1566.

FERRO, G., Teatro d'imprese, Venetia, apresso Giacomo Sarzina., 1623.

GARCÍA ARRANZ, J. J., «La salamandra: distintas interpretaciones gráficas de un mito literario tradicional», Norba-Arte, X, 1990, pp. 53-68.

GARONE, M., GALINA RUSSELL, I. y GODINAS, L. (eds.), De la piedra al píxel. Reflexiones en torno a las edades del libro, México, UNAM, 2019.

GIOVIO, P., Dialogo de las empresas militares y amorosas... con un razonamiento a esse proposito del magnifico Señor Ludovico Domeniqui [sic]... traduzido en romance castellano por Alonso de Ulloa. Añadimos a esto las empresas heroicas y morales del Señor Gabriel Symeón, en León de Francia, en casa de Guglielmo Roville, 1561.

CIAN, V. (ed., notas e ilustraciones), Il cortegiano del conte Baldesar Castiglione, Firenze, G. C. Sansoni, 1894.

LÓPEZ POZA, S., «Divisas ocasionales o invenciones españolas en un cancionero manuscrito del duque Charles III de Croÿ», Hipogrifo, $\mathrm{n}^{\circ}$ 8.1, 2020, pp. 453-469, DOI: http://dx.doi.org/10.13035/H.2020.08.01.31

LÓPEZ POZA, S., «Emblemática aplicada y artificios de la cultura visual en los juegos caballerescos del Siglo de Oro», en J. Ma. DÍEZ BORQUE (dir.), I. OSUNA y E. LLERGO (eds.), Cultura oral, visual y escrita en la España de los Siglos de Oro, Madrid, Visor, 2010, pp. 413-462. 
LÓPEZ POZA, S. y SAAVEDRA PLACES, Á., «Symbola: divisas históricas (emblemática personal) en la Europa medieval y moderna. Diseño e implementación de la base de datos y la interfaz de consulta», en N. RODRÍGUEZ-ORTEGA (coord.). «Humanidades digitales: sociedades, políticas, saberes II», Artnodes, no 23 (2019), pp. 49-61. <http://dx.doi.org/10.7238/ a.v0i23.3216>.

MACEIRAS, A., Empresas o divisas históricas: un catálogo basado en fuentes de 1511 a 1629, A Coruña, SIELAE \& Society for Emblem Studies, 2017.

NEUGEBAUER, S., Selectorum symbolorvm heroicorvm centvria gemina, Fránkfurt [del Meno], Jakob de Zetter, Lukas Jennis, 1619.

PALLISER, F. B., Historic Devices, Badges and War-Cries, London, Sampson Low, 1870.

PALASI, Ph., Mots, cris et devises emblématiques dans l'Europe occidentale médiévale et moderne, Paris, Picard, 2016.

PARADIN, C., Devises heroïques, Lyons, Jean de Tournes y Guillaume Gazeau, 1557.

PENA SUEIRO, N., «El portal BIDISO: pasado, presente y futuro inmediato. Un ejemplo de evolución en aplicaciones de las HD», Studia Aurea: Revista de Literatura Española y Teoría Literaria del Renacimiento y Siglo de Oro, 11, 2017, pp. 73-92.

PARNOTTE, A., «Genèse et aventure éditoriale du 'Dialogo delle imprese militari et amorose' de Giovio et de 'Le imprese heroiche et morali' de Symeony chez Roville, 1555-1559, à la lumière du ms. Ashburnham 1376», en S. D'AMICO y S. GAMBINO LONGO (eds.), Le savoir italien sous les presses lyonnaises à la Renaissance, Genève, Droz, 2017, pp. 489-559.

PICINELLI, F., Mondo simbolico, Milano, per lo Stampatore Archiepiscopale, 1653.

PITTONI, B. y DOLCE, L., Imprese di diversi prencipi, duchi, signori e d'altri personaggi et huomini illustri [Venetia, s. i., 1562].

PRIANI SAISÓ, E., «El texto digital y la disyuntiva de las humanidades digitales», Palabra Clave, vol. 18, no 4, 2015, pp. 1215-1238.

ROLET, A., «Aux sources de l'emblème: blasons et devises», Littérature, 145, 2007/1, pp. 53-78.

RUSCELLI, G., Le imprese illustri, Venetia, Franciscus Rampazetto, 1566.

SIMEONI, G., Le imprese heroiche et morali retrovate da M. Gabriello Symeoni Fiorentino, in Lyone, apresso Guglielmo Roviglio, 1559.

SPENCE, P., «Edición académica en la era digital: modelos, difusión y proceso de investigación», Anuario Lope de Vega, 20, 2014, pp. 47-83. 
TESAURO, E., Il cannocchiale aristotelico o sia idea delle argutezze heroiche vulgarmente chiamate imprese et di tutta l'arte simbolica et lapidaria..., Torino, Gio. Sinibaldo, 1654.

TUNG, M., Impresa Index to the Collections of Paradin, Giovio, Simeoni, Pittoni, Ruscelli, Contile, Camilli, Capaccio, Bargagli, and Typotius, New York, AMS Press, 2006.

TYPOTIUS, J., Symbola diuina \& humana pontificum imperatorum regum..., Praga, [s.i.], 1601-1603.

VALERIANO, P., Hieroglyphica sive de sacris Aegyptiorum literis commentarii, Basileae, [Michael Isengrin], 1556.

YOUNG, A. R., The English Tournament Imprese, New York, AMS, 1988.

\section{Apéndice}

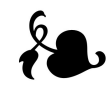

Algunas de las fuentes primarias que han proporcionado datos sobre las divisas insertas en Symbola:

- Batallas y quinquagenas, Gonzalo Fernández de Oviedo, 1535-1556.

○ Edición RAH, (1983-2002), 4 vol.

○ Ms. 11657 BNE.

- Ms. 3135 BNE.

- Ms. 9/5387 Biblioteca de la Real Academia de la Historia.

- Ms. 9/4023 Biblioteca de la Real Academia de la Historia.

- Ms. 359 Biblioteca de la Univrsidad de Salamanca.

- Cancionero de Rennert, principios del siglo XVI.

- Cancionero General, Hernando del Castillo, 1511.

- Crónica de la ínclita y coronada ciudad de Valencia, Rafael Martín de Viciana.

- Delle imprese, Giulio Cesare Capaccio, 1592.

- Devises heroïques, Claude Paradin, 1551.

- Diallogo delle imprese militari et amorose, Paolo Giovio, 1555.

- El felicíssimo viaje del muy alto y muy poderoso príncipe don Phelippe, Calvete de Estrella, 1552.

- Empresas de los reyes de Castilla, Francisco Gómez de la Reguera y Serna [1629].

- Imprese di diversi prencipi, duchi, signori e d'altri personaggi et huomini illustri, Battista Pittoni y Ludovico Dolce, 1562. 
- Imprese nobili et ingenose di diversi prencipi et d'altri personaggi illustri nell'arme et nelle lettere, Ludovico Dolce, 1566.

- Le imprese illustri, 1566, Girolamo Ruscelli.

- Le imprese, Scipione Bargagli, 1594.

- Libro de linajes y armas, Gonzalo Fernández de Oviedo, 1517-1523.

- Ragionamento di Luca Contile sopra la propietà delle imprese, Luca Contile, 1574.

- Relación de la fiesta de la sortija celebrada en Madrid el 31 de marzo de 1590 (anónima).

- Relación de las fiestas caballerescas de Valladolid de 1527 en honor al nacimiento de Felipe II de España (anónima).

- Selectorum symbolorum heroicorum centuria gemina, Salomon Neugebauer (1619).

- Symbola divina et humana. Pontificum, imperatorum, regum, Jacobus Typotius, 1601-1603.

- Symbola Romanorum imperatorum occidentalisett orientalis... per Octavium de Strada [dos manuscritos, de 1591 y 1595].

- $\quad$ Teatro d'imprese, Giovanni Ferro, 1623.

- Tratado copioso y verdadero de la determinación del gran Monarcha Phelipe II para el casamiento del III con la Sereníssima Margarita de Austria, [Juan Esquerdo], 1599.

Sagrario López Poza

Universidade da Coruña

Catedrática de Literatura Española https://orcid.org/0000-0003-1852-7938 sagrario.lopez.poza@udc.es

Nieves Pena Sueiro

Universidade da Coruña Doctora en Filología Hispánica

Profesora Titular de Universidad https://orcid.org/0000-0003-2028-2765 nieves.pena.sueiro@udc.es 
